\title{
PRESCRIBING AND SENSITIVITY PATTERNS OF ANTIMICROBIALS IN UNCOMPLICATED URINARY TRACT INFECTIONS IN FEMALES
}

\author{
Sah Om P.*, Danegulu Ranjana, Khadka Jagat, Khan Gulam M., Manadhar Santosh, Poudel Dr. Badri, Shah Shiv N., Yadav \\ Randhir. \\ School of Health and Allied Sciences, Pokhara University, Lekhnath, Kaski, Nepal \\ "All authors have equal contribution as first author." \\ *Corresponding author:opsnepal@yahoo.com
}

\begin{abstract}
The overuse and misuse of antibiotics have been related to growing emergence of bacterial resistance worldwide. The aim of this present study was to detect the causative agents of urinary tract infection, assess the pattern of antimicrobial prescription along with the antimicrobial sensitivity pattern.Patient information was obtained by interviewing the patients and through their medical record files. Antibiotic sensitivity testing was performed by disc diffusion. The study showed that UTI was mostly prevalent in females of age group 20-30. Escherichia coli were the predominant (64.4\%) bacterial pathogen followed by Klebsiella species (13.3\%), Pseudomonas species $(3.8 \%)$ and others.Most of the strains of $E$. coli were resistant to cephalexin whereas sensitive to cefpodoxime, amikacin, gentamycin and nitrofurantoin. Most of the urinary isolates showed high degree of resistance to cephalexin, norfloxacin and nalidixic acid.A single antibiotic was most commonly prescribed in both the hospitals, however, more than three antibiotics were also found to be prescribed.This study revealed that $E$. coli was the predominant bacterial pathogen of uncomplicated UTIs in both hospitals. It also demonstrated an increasing resistance to cephalexin, norfloxacin and nalidixic acid. Thus, formulation of a policy for hospital antibiotic use is a must for proper use of antibiotics and to ensure safe and efficient treatment of UTIs.

Keywords: UTI, Escherichia coli, cephalexin, prescribing, sensitivity
\end{abstract}

\section{GENERAL INTRODUCTION}

Urinary Tract Infections (UTI) is a heterogeneous disease, which can be divided into several types of infection, such as acute, uncomplicated bacterial pyelonephritis, complicated UTI, recurrent cystitis and asymptomatic bacteriuria (Akortha and Ibadin, 2010) ${ }^{1}$. Urinary tract infection (UTI) is defined as significant bacteriuria in the presence of symptoms.

The urinary tract is normally sterile. Uncomplicated UTI involves the urinary bladder in a host without underlying renal or neurologic disease. The clinical entity is termed cystitis and represents bladder mucosal invasion, most often by enteric coliform bacteria (e.g.Escherichia coli) that inhabit the periurethral vaginal introitus and ascend into the bladder via the urethra.

Sexual intercourse may promote this migration, and cystitis is common in otherwise healthy young women. Urine is generally a good culture medium; factors unfavorable for bacterial growth include a low $\mathrm{pH}$ (5.5 or less), a high concentration of urea, and the presence of organic acids derived from a diet that includes fruits and protein.

It is the most common infection experienced by both male and female particularly responsible for discomfort in elderly patients, thus representing a risk of bacteremia, septic shock, respiratory distress syndrome and death (Gradwohl et al., $2005)^{2}$. Infection of adjacent structures such as prostrate and epididymis is also included in this entity. Infection of urinary tract is amongst the most common bacterial infections that prompt patients to seek medical advice second only to infection of respiratory tract (Jha and Bapat, 2005) ? $^{3}$.The geographical distribution of UTI amongst the Nepalese population is $0.57 \%$ in the mountains and $0.45 \%$ is estimated to be in planes.

\section{Prescribing patterns}

Prescribing is the act of determining which drug for which patient at an appropriate dosage regimen and with optimal duration of treatment. This is dynamic, highly individualized and involved medical, social and marketing forces. Inappropriate prescribing including supraoptimal or suboptimal choice of medication, higher or lower drug dosage, inappropriate duration, therapeutic duplication, potentially dangerous drug-drug interaction, prescribe an expensive drug when a cheaper and equally effective agent is available, are important health care problem.

Factors influencing prescribing patterns:

System factors: System or exogenous or structural environment factors which affect prescribing pattern are drug policies, hospital formularies, practice organization, influence of pharmaceutical companies, fragmentation of care, overabundance of drug therapy option and information quality.

Prescriber factors: Differences in characteristics of prescriber knowledge ability and experience in the field of specialty would affect the choice of drug to be used. Internal factors that would affect prescribing patterns include an inadequate training or practices, outdated medical knowledge, lack of continuing education, inadequate drug information especially its effectiveness or adverse reaction 
and drug cost, forgetfulness and temptation to the offer from pharmaceutical industries

Patients or family factors: Patients or families who have a different backgrounds or cultural belief demand for drug or treatment which may be inappropriate; for example, patients demand an injected drug instead of an oral drug because they believed that it is more potent than the oral one and the disease will be cured more rapidly.

UTI are often treated with different broad-spectrum antimicrobials suspecting infection with resistant organisms though a narrow spectrum of activity may be appropriate. In general, $\quad \beta$-lactam antibiotics, trimethoprimsulphamethoxazole (TMP-SMX) and fluoroquinolones are used most often in uncomplicated UTI. In the case of a highrisk patient profile due to complicated factors, quinolones might be added to the armamentarium of treatment. However, the antibiotic of choice is currently highly dependent on the local situation with regard to the antibiotic resistance of the pathogenic bacteria (Matute AJ et al., $2004)^{4}$. However, the extensive use of antimicrobial agents has invariably resulted in the development of antimicrobial resistance, which, in recent years, has become a major problem worldwide (Dimitrov et al., 2004) $)^{5}$. In UTI, antimicrobial therapy is initiated even before the result of urine culture is available. Hence, there exists a great need for antimicrobial resistance surveillance at local, national and international level from time to time (Khan and Zaman, 2006) ${ }^{6}$.

\section{METHODS}

\section{Collection of suspected prescription}

The prescription of female patient visiting the hospital with sign and symptoms of UTI were enrolled in our study for the prescribing and sensitivity pattern (Huang and Stafford, 2002) ${ }^{7}$.

\section{Inclusion criteria}

The female patient visiting the hospital with the following sign and symptoms were enrolled in our study.

Flank pain, Urine urgency, Urine frequency, Fever,Rigors,Burning micturition,Itching vulva,History of Discharge,Painful intercourse, Foul odor.

\section{Exclusion criteria}

Severe anemia (hemoglobin $<7 \mathrm{gm} / \mathrm{dl}$.), Presence of heart disease with signs of cardiac failure,severerenal and hepatic diseases,documented tuberculosis with ongoing treatment,Associated other severe diseases that require special care or surgical intervention,Pregnancy and Diabetes.

\section{Total number of enrollment}

Total no of patients: 175

Minimum 50 patients suffering from UTI from each hospital.

\section{Noting of patient history and empirical treatment} therapy

Performa was filled up with patient name, age, address. Along with them, patient's history of illness with empirical treatment and investigative suggestions were also noted.

\section{Collection of urine sample}

Freshly voided mid-stream urine with labia separated of suspected females was collected into a wide mouthed sterile container. Once collected, the sample was transferred to the laboratory without delay within $30 \mathrm{~min}$. If a delay of more than 1-2 hours was to be made than it was stored in a refrigerator at $4^{\circ} \mathrm{C}$ or by collection and transportation in a container with boric acid at bacteriostatic concentration of $1.8 \%$ (Collee et al., 1996) ${ }^{8}$.

\section{Preparation of culture media}

Different culture media were prepared which ware used according to standard method.

\section{Culture and isolation of pathogens}

Clean catch midstream collected urine samples was inoculated on Mac-Conkeyand Blood Agar media using calibrated platinum loop following standardbacteriological technique. The primary inoculum was made by a loop and the material was spread into four quadrants of the plate. A platinum or nichrome wire (24 S.W.G. size) loop of 2-4 mm diameter with 2 to 3 inches long wire was first sterilized in the Bunsen flame and cooled by touching an uninoculated part of the medium. Then, a loopful of specimen was gently smeared onto the surface of a well dried plate of medium near the peripheral area. The inoculum was then thinly spread in parallel lines in different segments of the plate. The loop was sterilized between different sets of streaks. Finally, the plate was incubated at $37^{\circ} \mathrm{C}$ for overnight. Pure bacterialcolonies counting 100,000 or more was considered as significant and were subjected to identification based on colony characters and biochemical tests (Uwaezuoke and Ogbulie, 2006) ${ }^{9}$.

\section{Bacterial identification}

Colonial Morphology: The appearance of bacterial colony on the surface of a solid medium was used for the primary identification.

Smears prepared from the bacterial colony were examined by staining methods. Gram's staining divide bacteria into Gram-positive and Gram-negative. It is the most widely used stain in medical bacteriology.

Gram-positive bacteria resist decolourisation and stain violet while Gram-negative bacteria and other cells (pus cells) are decolourised and stain pink with counterstain.

\section{Biochemical test}

\section{Indole Test}

Indole is one of the degradation products of amino acid metabolism. It is useful in identifying E. coli. This test was used to determine whether bacteria possess the enzyme tryptophanase which will produce the byproduct indole from the catabolism of tryptophan. Kovac's reagent was used after inoculation and incubation to read the results Kovac's reagent contains $\mathrm{HCl}$ and dimethylaminobenzaldehyde (DMABA) dissolved in amyl alcohol, which forms a layer on top of the inoculating medium which causes the red color to be very easily visible and distinguishable. The alcohol in Kovac's reagent floats on the media and another chemical in the reagent react with indole to form a red color in the alcohol layer. A positive test produced pink/purple colour at interface and the organism was E. coli and a negative test remained colorless. 
Methyl Red/Voges Proskauer Broth

\section{Voges-Proskauer Test}

Some microbes do not produce stable acids from glucose fermentation but instead produce 2,3 butanediol from glucose breakdown and in the process an intermediate chemical acetoin is produced. Two reagents Barritt'sa (alpha-naphthol) and Barritt's B (KOH) was added to a 48 hour culture of the MRVP broth. A pipette was taken to aliquot out a small amount of the broth to do the VP test and the broth was returned for further incubation for the MR test if necessary. A wine red color change with the addition of Barritt's reagents A and B is a positive test detecting the presence of acetoin and therefore 2, 3 butanediol; a brown or copper color is negative.

\section{Methyl Red Test}

The methyl red test is used to determine organisms that ferment glucose to a stable acid end product in a great degree, lowering the $\mathrm{pH}$ of the system despite the presence of buffer. Media for the methyl red test (MRVP media) was prepared and contained peptone, glucose, and a phosphate buffer. Broth was inoculated and incubated at $30^{\circ} \mathrm{C}$ for five days to allow stable acids to be produced. At the end of the fifth day, methyl red indicator was added. Methyl red indicator is red at $\mathrm{pH}$ less than 4.4 and yellow at $\mathrm{pH}$ above 6.0 , so a red result was labeled positive, and a yellow result negative.

\section{Citrate Utilization Test}

Simmon's Citrate agar is used to determine if an organism can use citrate as its only carbon source using the enzyme citrase (also contains ammonia as the only nitrogen source). Citrate utilization is an aerobic process and a slant tube is used to increase exposure of bacterial growth to the air; inoculate the slant. $\mathrm{pH}$ indicator is Bromthymol blue, which is green at neutral $\mathrm{pH}$ but turns Prussian blue at $\mathrm{pH}$ levels above 7.6

\section{Triple Sugar Iron Agar}

TSI Agar slants contain 2\% polypeptone, $1 \%$ lactose, $1 \%$ sucrose, $1 \%$ glucose, phenol red $\mathrm{pH}$ indictor, and ferric ammonium citrate. Utilization of sugars proceeds in much the same way as in sugar broth tests, with acid production changing a $\mathrm{pH}$ indicator. Specifically, fermentation of lactose/sucrose and glucose causes the entire tube to be yellow. Fermentation of glucose alone causes the butt of the culture to be yellow, but the shallow slant portion turns red as glucose is oxidatively exhausted and peptone is metabolized, producing $\mathrm{NH}_{3}$ resulting in an alkaline $\mathrm{pH}$. Gas production during the utilization of sugar is indicated by fissures or pockets in the slant. Some bacteria also produce hydrogen sulfide $\left(\mathrm{H}_{2} \mathrm{~S}\right)$ by reducing thiosulfate in the medium or breaking down cysteine in the peptone. Ferric ammonium citrate reacts with hydrogen sulfide to produce a black precipitate in the butt of the agar. The slants were made from commercially prepared TSI mix and poured to allow the butt of the agar to be four centimeters deep, and the slants were inoculated. The slants were incubated for twenty-four hours at $37^{\circ} \mathrm{C}$ and tests were read for all three sugars as well as gas and $\mathrm{H}_{2} \mathrm{~S}$ production.

\section{Preparation of MacFarland turbidity standard}

$0.5 \mathrm{ml}$ of $0.048 \mathrm{M}$ Barium chloride was added in $66.5 \mathrm{ml}$ of $0.36 \mathrm{~N}$ sulfuric acid and $5 \mathrm{ml}$ of it was aliquoted into screwcapped tubes of same size and was stored in dark at room temperature (Shaikh et al., 2005) ${ }^{10}$.

\section{Preparation of inoculum}

Four or five well isolated colonies of same morphological type were touched with a sterile wire loop, suspended into tubes containing $5 \mathrm{ml}$ of MHB. The medium was then incubated at $35^{\circ} \mathrm{C}$ for $2-8$ hours until the turbidity reached or exceeded that of 0.5 MacFarland standards (already prepared). If the suspension was exceeded, it was diluted with broth and was visually comparable to the 0.5 MacFarland standards (Shaikh et al., 2005) ${ }^{10}$.

\section{Inoculation of MHA plates}

A sterile swab was dipped into the broth suspension of the organisms within 15 minutes of standardization. Excess inoculum was removed by rotating the swab several times against the wall of the tube above the fluid level. The entire surface of an MHA plate was then streaked evenly in three/two directions approximately 60 degrees from each other (Shaikh et al., 2005) ${ }^{10}$.

\section{Antimicrobial sensitivity test}

Antimicrobial sensitivity test was performed by disc diffusion method (Kirby-Bauer's technique) using commercially available disc. The antimicrobial impregnated discs was placed with sterile forceps on the Muller Hinton Agar surface such that each disc was at least $24 \mathrm{~mm}$ from the other disc avoiding overlap during incubation. Then, it was incubated at $37^{\circ} \mathrm{C}$ for $18-24$ hours. These test discs will be of the antimicrobials observed in prescription pattern (Khan and Zaman, 2006) ${ }^{6}$. At the end of incubation period, the diameter of zones of inhibition around each disc was measured with a Vernier caliper on the back of the plate, with reflected light against a dark non-reflective background. The zone of diameter for each antimicrobial agent was then interpreted as resistant/intermittent/sensitive by comparing with the standard given by the HI Media Laboratories Pvt. Ltd. (Shaikh et al., 2005) ${ }^{10}$.

\section{Noting of isolated bacteria and sensitivity pattern}

The bacteria responsible for the pathogenesis were noted after isolation of bacteria with culture and biochemical tests. Along with it, the sensitivity pattern of the antimicrobials was also noted down.

\section{Noting of final diagnosis and prescribing pattern}

The final diagnosis made after seeing the report by the physicians and the drug prescribed after it was noted down.

\section{Data analysis}

Statistical Package for Social Sciences for windows (SPSS), version 11.5 was used for statistical analysis.

\section{RESULTS}

A total of 175 urine sample were collected, out of these 104 patients' urine were found to have significant bacterial growth. Total six species of bacteria were isolated viz. E.coli 67(64.4\%), Proteus species 3(2.9\%), Klebsiella species 14(13.3\%), Staphylococcusaureus 11(10.6\%), Citrobacter species 5(4.8\%) and Pseudomonas aureginosa 4(3.8\%). 
Table 1: Respondence of UTI in relation to age distribution of female patients

\begin{tabular}{|ll|l|l|l|}
\hline & & \multicolumn{2}{|l|}{ Hospital } & \multirow{2}{*}{ Total } \\
\cline { 2 - 4 } & A & B & $26.9 \%$ \\
& Age group & $20.0 \%$ & $30.9 \%$ & $16.6 \%$ \\
& $10-20$ & $13.8 \%$ & $18.2 \%$ & $29.1 \%$ \\
& $20-30$ & $36.9 \%$ & $24.5 \%$ & $13.7 \%$ \\
& $30-40$ & $10.8 \%$ & $15.5 \%$ & $6.9 \%$ \\
& $40-50$ & $9.2 \%$ & $5.5 \%$ & $2.9 \%$ \\
& $50-60$ & $3.1 \%$ & $2.7 \%$ & $2.9 \%$ \\
Total & $60-70$ & $3.1 \%$ & $2.7 \%$ & $1.1 \%$ \\
& $>70$ & $3.1 \%$ & $100.0 \%$ & $100.0 \%$ \\
\hline
\end{tabular}

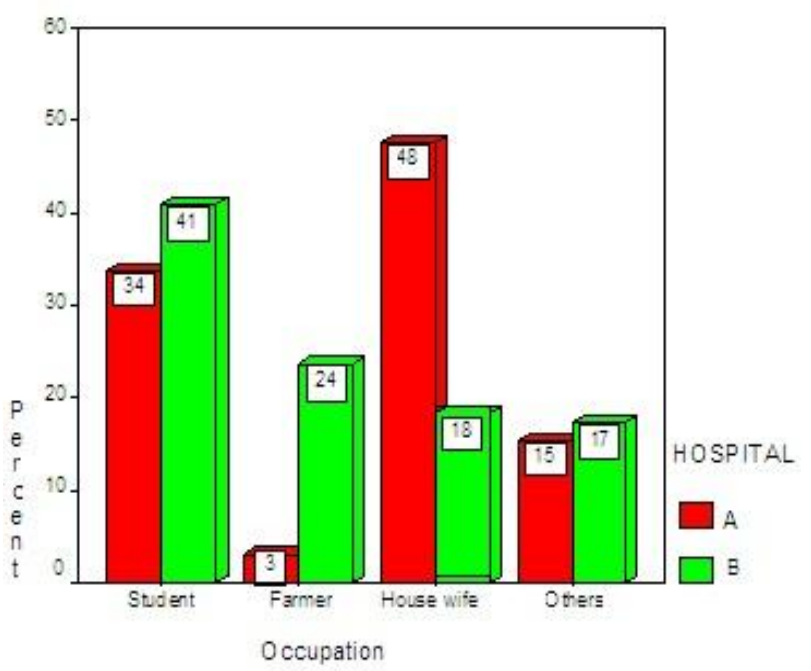

Figure 1: Shows the incidence of UTI by occupational groups

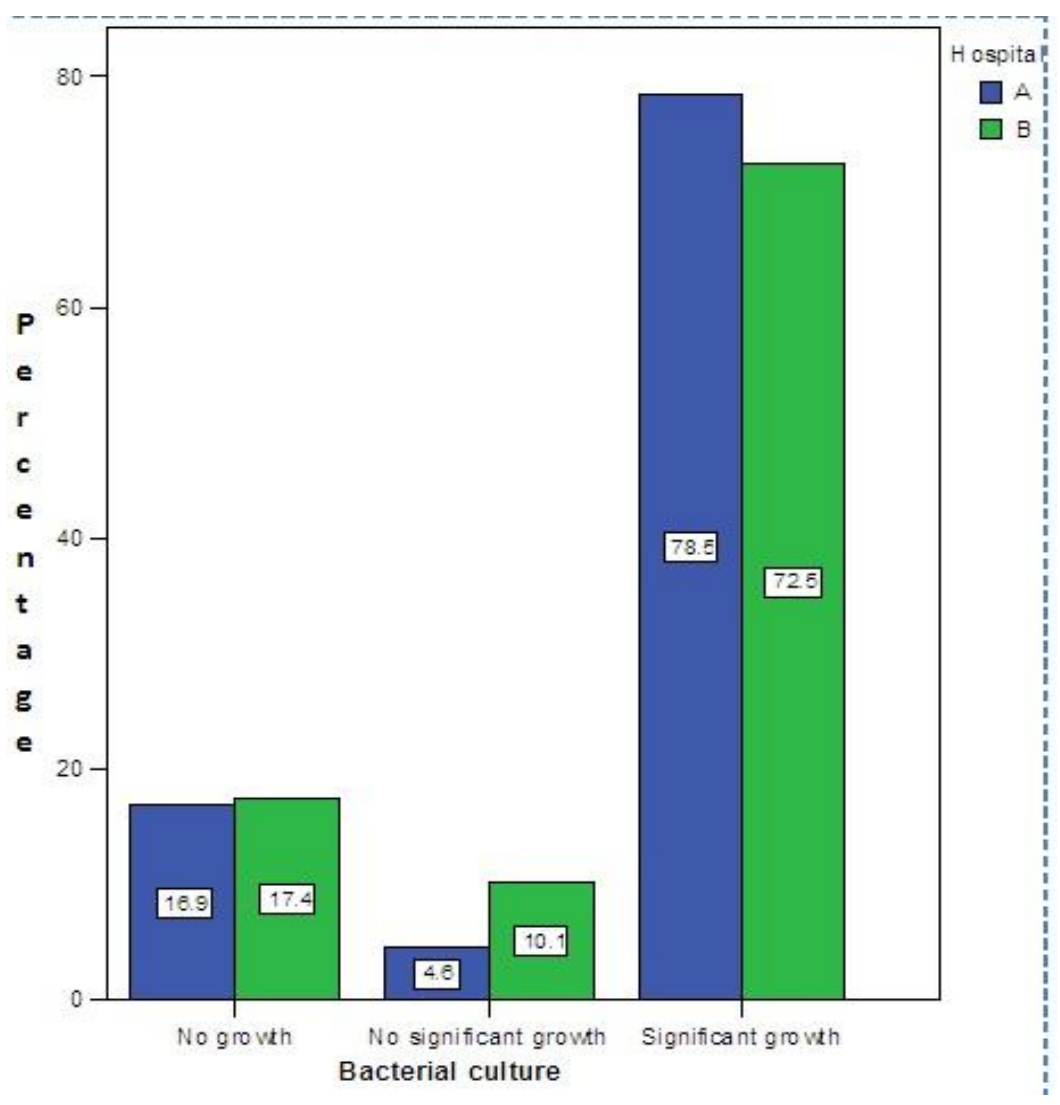

Figure 2: Bacterial growth positive rate in urine samples collected. 


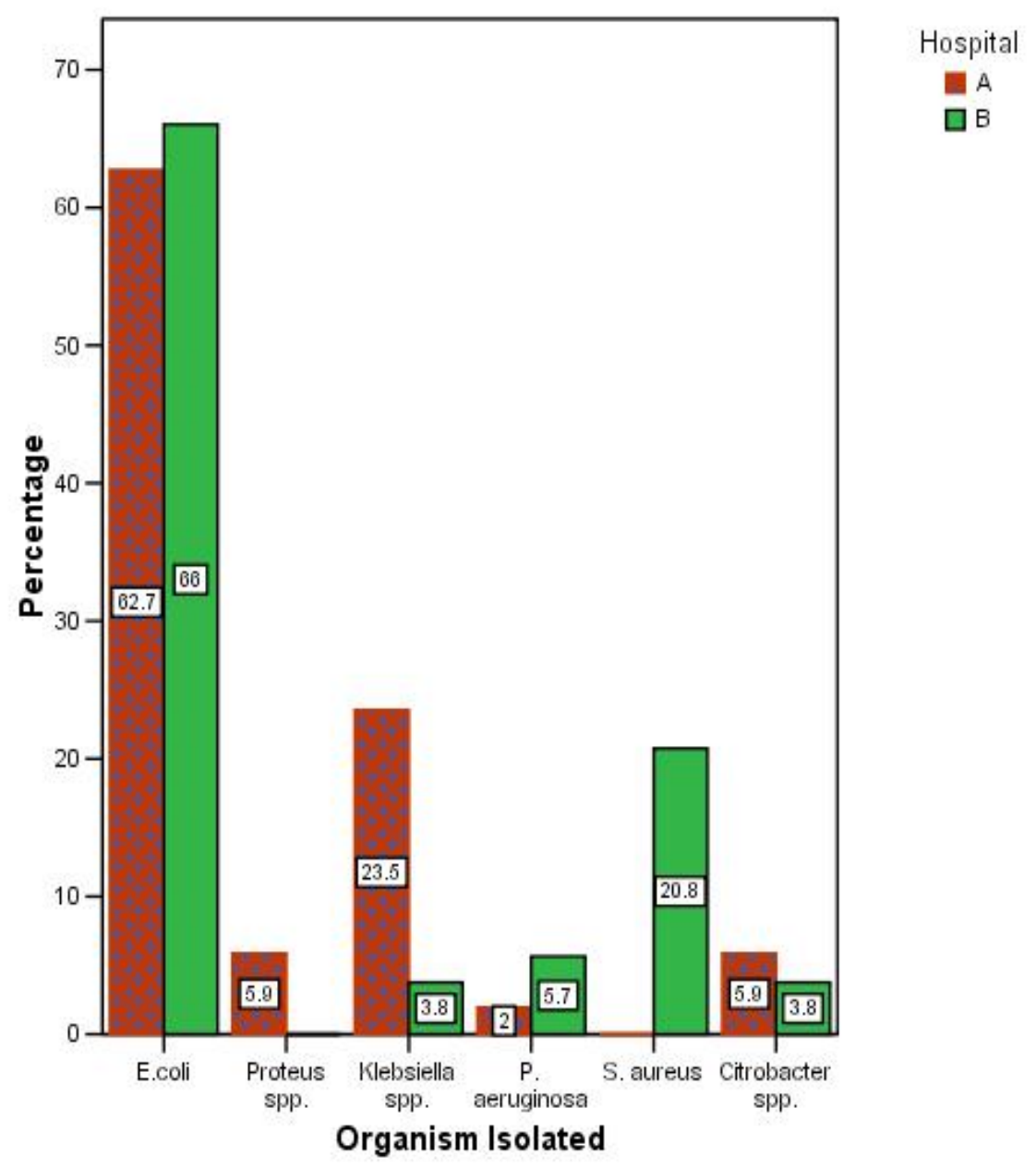

Figure 3. Frequency of different pathogens isolated from urine samples of females with uncomplicated UTI $(\mathrm{N}=104)$ in both hospitals.

Table 2: Overall sensitivity Pattern of antimicrobials in hospital A and hospital B

\begin{tabular}{|l|l|}
\hline Hospital A & $\begin{array}{l}\text { Cefpodoxime }(100 \%)>\text { Alizarin }(98.0 \%)>\text { Nitrofurantoin }(95.9 \%)>\text { Gentamycin }(94.1 \%) \\
\text { Azithromycin }(88.1 \%)>\text { Cotrimoxazle }(60.9 \%)>\text { Ciprofloxacin }(58.1 \%)>\text { Ofloxacin }(53.3 \%)> \\
\text { Cefixime }(44.7 \%)=\text { Norfloxacin }(44.7 \%)>\text { Nalidixic Acid }(35.7 \%)>\text { Amoxycillin }(33.3 \%)> \\
\text { Cephalexime }(25.5 \%) .\end{array}$ \\
\hline Hospital B & $\begin{array}{l}\text { Azithromycin }(100 \%)>\text { Amikacin }(80.3 \%)>\text { Gentamycin }(72.3 \%)>\text { Ciprofloxacin }(56.8 \%)> \\
\text { Nitrofurantoin }(54.2 \%)>\text { Levofloxacin }(53.3 \%>\text { Amoxycillin }(53.1 \%)>\text { Cotrimoxazole }(48.5 \%) \\
>\text { Cefixime }(47.1 \%)>\text { Ofloxacin }(45.7 \%)>\text { Cefpodoxime }(45.5 \%)>\text { Nalidixic Acid }(40.4 \%> \\
\text { Norfloxacin }(31.0 \%)>\text { Cephalexime }(20.8 \%)>\text { Other antibiotics }(11.1 \%) .\end{array}$ \\
\end{tabular}


Table 3: Frequency of antibiotics prescribed in respective hospitals.

\begin{tabular}{|c|c|c|c|c|}
\hline & & HOSP & & Total \\
\hline & & A & $\mathrm{B}$ & \\
\hline Treatment & Amikacin & $3.8 \%$ & & $1.3 \%$ \\
\hline & Amoxycillin & & $11.9 \%$ & $7.8 \%$ \\
\hline & Azithromycin & $9.6 \%$ & $7.9 \%$ & $8.5 \%$ \\
\hline & Cefpodoxime & $1.9 \%$ & $2.0 \%$ & $2.0 \%$ \\
\hline & Cefixime & $3.8 \%$ & $14.9 \%$ & $11.1 \%$ \\
\hline & Ofloxacin & $28.8 \%$ & $21.8 \%$ & $24.2 \%$ \\
\hline & Ceftriaxone & $1.9 \%$ & $5.9 \%$ & $4.6 \%$ \\
\hline & Gentamycin & $5.8 \%$ & $1.0 \%$ & $2.6 \%$ \\
\hline & Ciprofloxacin & & $6.9 \%$ & $4.6 \%$ \\
\hline & Clotrimazole & & $2.0 \%$ & $1.3 \%$ \\
\hline & Metronidazole & & $1.0 \%$ & $.7 \%$ \\
\hline & Cloxacillin & & $1.0 \%$ & $.7 \%$ \\
\hline & Levofloxacin & & $1.0 \%$ & $.7 \%$ \\
\hline & Nitrofurantoin & $19.2 \%$ & & $6.5 \%$ \\
\hline & Azithromycin Cefpodoxime & & $2.0 \%$ & $1.3 \%$ \\
\hline & Azithromycin Amoxycillin & & $2.0 \%$ & $1.3 \%$ \\
\hline & Azithromycin Ceftriaxone & & $1.0 \%$ & $.7 \%$ \\
\hline & Cefixime Azithromycin & $1.9 \%$ & $10.9 \%$ & $7.8 \%$ \\
\hline & Gentamycin Azithromycin & $1.9 \%$ & & $.7 \%$ \\
\hline & Gentamycin Cefixime & $1.9 \%$ & & $.7 \%$ \\
\hline & Gentamycin Ceftriaxone & $5.8 \%$ & & $2.0 \%$ \\
\hline & Nitrofurantoin Doxycycline & $1.9 \%$ & & $.7 \%$ \\
\hline & Ofloxacin Azithromycin & $1.9 \%$ & & $.7 \%$ \\
\hline & Ofloxacin Cefixime & $3.8 \%$ & & $1.3 \%$ \\
\hline & Ofloxacin Metronidazole & & $1.0 \%$ & $.7 \%$ \\
\hline & Ceftriaxone Cefixime & $1.9 \%$ & & $.7 \%$ \\
\hline & Ceftriaxone Azithromycin & $3.8 \%$ & $1.0 \%$ & $2.0 \%$ \\
\hline & Gentamycin Ampicillin Azithromycin & & $1.0 \%$ & $.7 \%$ \\
\hline & Cefixime Azithromycin Ofloxacin & & $1.0 \%$ & $.7 \%$ \\
\hline & Clotrimazole Cefixime Azithromycin & & $1.0 \%$ & $.7 \%$ \\
\hline & $\begin{array}{l}\text { Clotrimazole Metronidazole Cefixime } \\
\text { Azithromycin }\end{array}$ & & $1.0 \%$ & $.7 \%$ \\
\hline & Ciprofloxacin Azithromycin & & $1.0 \%$ & $.7 \%$ \\
\hline Total & & $100.0 \%$ & $100.0 \%$ & $100.0 \%$ \\
\hline
\end{tabular}

Table 4: Frequency of antibiotics prescribed in hospital A and hospital B.

\begin{tabular}{|ll|r|r|r|}
\hline & \multicolumn{2}{|c|}{ HOSPITAL } & \multicolumn{2}{|c|}{ Total } \\
\hline & & $\mathrm{A}$ & $\mathrm{B}$ & \\
\hline No. of antibiotics & 1 antibiotic & $75.0 \%$ & $77.2 \%$ & $76.5 \%$ \\
& 2 antibiotics & $25.0 \%$ & $18.8 \%$ & $20.9 \%$ \\
& 3 antibiotics & & $3.0 \%$ & $2.0 \%$ \\
& $>3$ antibiotics & & $1.0 \%$ & $.7 \%$ \\
Total & & $100.0 \%$ & $100.0 \%$ & $100.0 \%$ \\
\hline
\end{tabular}




\section{DISCUSSION}

The antibiotic sensitivity pattern of organisms changes rapidly over a short period. It is especially true for developing countries where antibiotics are prescribed irrationally not only by the medical practitioners but the antibiotics are also purchased directly from the chemists (medicine shop keepers) without prescription. It has been advised that medical practitioners should be aware of the rising resistance of urinary pathogens to commonly prescribed antibiotics as well as the profile of antibiotic resistance within their community. Therefore, evaluation of sensitivity pattern is essential for rational and appropriate use of antibiotics. . Higher prevalence of $E$. coli followed by Klebsiella (13.5\%) and S. aureus (10.6\%) in this study resembles to the various studies done by different scientists in different parts of the world. $89.4 \%$ of gram negative bacilli are responsible for UTI and the only gram positive bacteria responsible for UTI was $S$. aureus which constitute $10.6 \%$ in our study. E. coli is dominant for outpatients as well as indoor patients.

\section{ACKNOWLEDGEMENT}

We wish to acknowledge with thanks the significant contribution made by Mr. Gulam Muhammad Khan, Program Coordinator, School of Health and Allied Sciences,

\section{REFERENCES}

1. Akortha EE, Ibadin OK. Incidence and Antibiotic Susceptibility Pattern of Staphylococcus aureus Amongst Patients with Urinary Tract Infection (UTI) in UBTH Benin City, Nigeria. Afr J Biotechnol 2008, 7, 1637-1640.

2. Gradwohl SE, Fonde KR, Harrison HR, Zoschnick LB, Urinary Tract Infection Guideline, Journal of University of Michigan,2005, 5, 121-125.

3. Jha N and Bapat SK, A Study of Sensitivity and Resistance of Pathogenic Microorganisms Causing UTI in Kathmandu Valley, Kathmandu University Medical Journal,2005, 3, 123-129.

4. MatuteAJ, HakE, Schurink and CAM, Resistance of uropathogens in symptomatic urinary tract infections in Leon, Nicaragua. Int. J. Antimicrob. Agents, 2004, 23, 506-509.

5. Dimitrov TS, Emara M, Awni F, Passadilla R, Etiology and Antibiotic Susceptibility Patterns of Community-Acquired Urinary Tract Infections in a Kuwait Hospital, Medical Principle Practice,2004, 13, 334 -339.

6. Khan Asad U, Zaman Mohad S, Multiple drug resistance pattern in Urinary Tract Infection patients in Aligarh,Biomedical Research,2006,17(3),9-12.

7. Huang ES, Stafford RS, National Patterns in the Treatment of Urinary Tract Infections in Women by Ambulatory Care Physicians, Internal Medicine,2002, 162(1),41-47.

8. Collee, JG,AG, Fraser, BP Marmion, Simmin. Mackie and McCortney practical medical microbiology. Pearson Professional, New York. 1996,P. 385.

9. Uwaezuoke JC,Ogbulie N, Antibiotic sensitivity pattern of urinary tract pathogens in Port-Harcourt, Nigeria. J. Appl. Sci. Environ. Manage,2006, 10, 103-107.

10. Shaikh N, Morone NE, Bost JE, Prevalence of Urinary Tract Infection in Childhood A Meta-Analysis,Pediatr Infect Dis J, 2008,27, 302-308.

11. Abeyagunawardena AS, Pathinayake CA, Abeysekera CK, Antibiotic Sensitivity Patterns in Childhood Urinary Tract Infections, Sri Lanka Journal of Child Health,2006,35, 55-60.

12. Arone F, Morrone LA, Bagetta D, Florio L, Lista MR, Bagetta G, Rational use of Antibiotics in Acute Uncomplicated Cystitis: a Pharmaco-epidemiological study, Journal of Chemotherapy,2006,17(2), 184-188.

13. Basnet BB, Acharya K, Karmacharya N, Dahal RK, Upreti HC and Rijal BP (2009) Multi Drug Resistance Patterns Of Urinary
Lekhnath, Kaski, for supervising throughout this project despite of his busy schedule.We would like to express our sincere gratitude to Dr. Badri Poudel, Physician, Charak Hospital and Research Centre, for supervising throughout this project despite of his busy schedule and providing space and lab in the hospital to carry out the project work. We would like to express our heartfelt gratitude to Mr. Jagat Khadka, Microbiologist, Western Regional Hospital, for supervising throughout this project despite of his busy schedule and providing space and lab in the hospital to carry out the project work. We are grateful to Mr. Niranjan Shrestha, Lecturer, School of Health and Allied Sciences, for helping in the statistical treatment and analysis of the data. We are very much indebted to all the staffs of Laboratory, Medical ward and Out Patient Pharmacy of Charak Hospital and Research Centre, Western Regional Hospital for their kind cooperation for this work. Finally, we would like to take this opportunity to thank all those patients whose participation has made this study possible.

\section{Conflicts of interest:}

It's me myself corresponding author of this article and assure you that nobody have conflicts of interest if we publish this article in your journal: JOURNAL OF DRUG DELIVERY AND THERAPEUTICS (JDDT).

Isolates In A Tertiary Care Hospital Of Nepal, Journal of Nepal Association for Medical Laboratory Sciences, 10, 47-52.

14. Blango MG and Mulvey MA, Persistence of Uropathogenic Escherichia coli in the Face of Multiple Antibiotics, Antimicrobial Agents Chemotherapy, 2008, 54(5), 1855-1863.

15. Bush IM, Metzger WI, Garlovsky I, Bush RB, Ablin RJ, Sadoughi $\mathrm{N}$, Urinary Tract Infection. Antibacterial Susceptibility Patterns, Urology, 1974,3(6), 697-700.

16. Cetin M, Ucar E, Guven O,Ocak S, Community-acquired Urinary Tract Infections in Southern Turkey: Etiology and Antimicrobial Resistance, Clinical Nephrology,2009,71(1),30-35.

17. Cheng CH, Tsai MH, Huang YC, Su LH, Tsau YK, Lin CJ, Chiu $\mathrm{CH}$, Lin TY, Antibiotic Resistance Patterns of Communityacquired Urinary Tract Infections in Children with Vesicoureteral Reflux Receiving Rrophylactic Antibiotic Therapy, Pediatrics,2008, 122(6), 1212-1217.

18. Das RN, Joshi HS, Gurung M, Shrestha N, Shivananda PG , Frequency and Susceptibility Profile of Pathogens Causing Urinary Tract Infections at a Tertiary Care Hospital in Western Nepal, Singapore Medical Journal,2006, 47(4), 281-285.

19. Dimitrov TS, Emara M, Awni F, Passadilla R, Etiology and Antibiotic Susceptibility Patterns of Community-Acquired Urinary Tract Infections in a Kuwait Hospital, Medical Principle Practice,2004,13,334-339.

20. Fadda G, Nicoletti G, Schito GC , Tempera G , Antimicrobial Susceptibility Patterns of Contemporary Pathogens from Uncomplicated Urinary Tract Infections Isolated in a Multicenter Italian Survey: Possible Impact on Guidelines, Journal of Chemotherapy,2005, 17(3), 251-257.

21. Farajzadeh S, Ghazanfari F, Esfandiarpour I, Shahesmaeili A, Rahnama Z Aghaei H , The Relationship Between Infantile Atopic Dermatitis and Urinary Tract Infection, Iran Journal Allergy Asthma Immunol,2009, 8(4), 211-214.

22. Ghedira L, Messaoudi A, Meriem B, Guediche C, Profile of Antimicrobial Resistance of Agents Causing Urinary Tract Infections in Children, Tunis Medical Journal,2004, 82(3), 299305 .

23. Heijer CD, Donker GA, Maes J, Stobberingh EE, Antibiotic susceptibility of Unselected Uropathogenic Escherichia coli from Female Dutch General Practice Patients: a Comparison of two Surveys with a 5 year Interval, Journal of Antimicrobial Chemotherapy,2007, 65(10),2128-2133. 
24. Huang ES ,Stafford RS, National Patterns in the Treatment of Urinary Tract Infections in Women by Ambulatory Care Physicians, Internal Medicine,2002, 162(1),41-47.

25. KarkiA, PradhanSB, Study of Bacteria Isolated from Urinary Tract Infections and Their Sensitivity Pattern, Journal of Nepal Medical Association, 2004, 43,200-203.

26. Kathy NS, McGowan KL, McDaniel YN , Schwartz JS, Prevalence of Urinary Tract Infection in Febrile Young Children in the Emergency Department, Official journal of the American Academy of Pediatrics, 1998,102-109.

27. Kattel HP, Mishra SK, Rijal BP, Pokhrel BM, Bacteriology of Urinary Tract Infection among Patients Attending Tribhuvan University Teaching Hospital Kathmandu,Nepal, Journal of NAMLS, 2008, 9, 25-29.

28. Kiffer CR, Mendes C, Oplustil CP, Sampaio JL, Antibiotic Resistance and Trend of Urinary Pathogens in General Outpatients from a Major Urban city, International Brazil Journal of Urology,2007, 33(1),42-48.

29. Kolawole AS, Kolawole O, Kandaki-Olukemi YT, Babatunde SK, Durowade K, Kolawole CF, Prevalence of Urinary Tract Infections (UTI) Among Patients Attending DalhatuAraf
Specialist Hospital, Lafia, Nasarawa State, Nigeria, International Journal of Medicine and Medical Sciences,2009, 1,163-167.

30. Lindstorm TB, Flataas AS , Behaviour Modification GroupTreatment of Children with Recurrent Lower Urinary Tract Infections, Scand Journal of Caring Science,2009, 14(4), 259-267.

31. Lutter SA, Currie ML, Mitz LB, Greenbaum LA , Antibiotic Resistance Patterns in Children Hospitalized for Urinary Tract Infections, Arch PediatriAdolesc Medicine,2005, 159(10), 924928.

32. Mangiarotti P, Pizzini C, Fanos V, Antibiotic Prophylaxis in Children with Relapsing Urinary Tract Infections, Journal of chemotherapy, 2000, 12(2),115-123.

33. Matutea AJ, Schurinkc CAM, McArthurd R, Alonsoe E, Paniaguae M, Asbeckc EV, Roskottc AM, Froelingc F, Rozenberg-Arskad M, Hoepelmanc IM, Resistance of Uropathogens in Symptomatic Urinary Tract Infections in León, Nicaragua, International Journal of Antimicrobial Agents,2004, 23(5),506-509.

34. Rai GK, Rai SK, Shah KP. Shrestha RM, Causative Agents of Urinary Tract Infections in Children and their Antibiotic Sensitivity Pattern: A Hospital Based Study, Nepal Medical College Journal,2008, 10(2),86-90. 